ОЖИРЕНИЕ — ОСНОВА МЕТАБОЛИЧЕСКОГО СИНДРОМА

(с) А.Ф. Вербовой*, Н.И. Вербовая, Ю.А. Долгих

Самарский государственный медицинский университет, Самара, Россия

Метаболический синдром является симптомокомплексом, который имеет в своей основе висцеральное ожирение и инсулинорезистентность. Его распространенность достаточно высока, что представляет большую проблему, так как данное состояние повышает риск развития сердечно-сосудистых заболеваний и смертности от них. Метаболический синдром включает в себя, помимо абдоминального ожирения, артериальную гипертензию, нарушения углеводного, липидного и пуринового обменов. Висцеральная жировая ткань играет ключевую роль в формировании инсулинорезистентности и остальных компонентов метаболического синдрома. Это обусловлено тем, что абдоминальный жир, в отличие от подкожного, синтезирует провоспалительные цитокины, а также адипокины - гормоны жировой ткани, которые участвуют в формировании резистентности к инсулину, влияют на углеводный, жировой обмен и сердечно-сосудистую систему. К ним относятся лептин, адипонектин, резистин, апелин и другие. Одни адипокины оказывают неблагоприятное воздействие на метаболизм и повышают кардиоваскулярные риски, в то время как другие, напротив, действуют положительно. Учитывая их роль в развитии компонентов метаболического синдрома, обсуждаются возможности терапевтического влияния на гормоны жировой ткани для улучшения метаболических процессов и профилактики связанных с ним осложнений.

КЛЮЧЕВЫЕ СЛОВА: метаболический синдром; ожирение; лептин; адипонектин; резистин; апелин.

\title{
OBESITY IS THE BASIS OF METABOLIC SYNDROME
}

(c) Andrey F. Verbovoy*, Nelly I. Verbovaya, Yuliya A. Dolgikh

Samara State Medical University, Samara, Russia

Metabolic syndrome is a symptom complex that is based on visceral obesity and insulin resistance. Its prevalence is quite high, which is a big problem, since this condition increases the risk of developing cardiovascular diseases and mortality from them. Metabolic syndrome includes, in addition to abdominal obesity, arterial hypertension, disorders of carbohydrate, lipid and purine metabolism. Visceral adipose tissue plays a key role in the formation of insulin resistance and other components of the metabolic syndrome. This is due to the fact that abdominal fat, in contrast to subcutaneous fat, synthesizes pro-inflammatory cytokines, as well as adipokines - adipose tissue hormones that are involved in the formation of insulin resistance, affect carbohydrate and fat metabolism and the cardiovascular system. These include leptin, adiponectin, resistin, apelin and others. Some adipokines have an adverse effect on metabolism and increase cardiovascular risks, while others, on the contrary, have a positive effect. Taking into account their role in the development of the components of the metabolic syndrome, the possibilities of a therapeutic effect on the hormones of adipose tissue to improve metabolic processes and prevent complications associated with it are discussed.

KEYWORDS: metabolic syndrome; obesity; leptin; adiponectin; resistin; apelin.

\section{ВВЕДЕНИЕ}

Метаболический синдром (МС) - это комплекс симптомов, характеризующийся сочетанием нарушений углеводного, липидного, пуринового обменов, а также артериальной гипертензией (АГ) [1].

Современное представление о МС сформировалось не сразу. На связь ожирения с повышением артериального давления (АД) и подагрой врачи обратили внимание еще много лет назад [2]. В дальнейшем представления о данном симптомокомплексе трансформировались. Лишь во второй половине XX в. было высказано предположение, что основными факторами развития этого состояния являются висцеральное (абдоминальное) ожирение и инсулинорезистентность (ИР). А сам термин «метаболический синдром» предложили в 1981 г. M. Hanefeld и W. Leoonardt [2].
В течение последних двух десятков лет данная патология находится в фокусе интересов врачей различных специальностей, о чем свидетельствует значительный рост числа работ, посвященных данной теме начиная с 2000-х годов. Столь пристальное внимание связано с высокой распространенностью МС в мире, а также с выраженным негативным влиянием этого состояния на развитие сахарного диабета (СД) 2 типа, сердечно-сосудистых заболеваний и смертность от них. Частота МС в популяции составляет 20-40\% [3]. Данный симптомокомплекс чаще встречается у лиц среднего и старшего возраста и достигает 30-40\%. Наличие МС в 3-6 раз повышает риск развития СД 2 типа и АГ. Увеличение численности пациентов с этими заболеваниями приводит к росту затрат здравоохранения на их лечение, хотя профилактическая терапия требует не меньших затрат. Распространенность АГ,

*Автор, ответственный за переписку / Corresponding author. 
по данным исследования ЭПОХА-АГ, за 19 лет увеличилась на 7,8\% [4]. Количество пациентов с диабетом за последние 18 лет увеличилось на 2,5 млн, при этом основной прирост происходил за счет СД 2 типа [5]. Число больных СД 2 типа на 31.12.2017 г. составило 4,15 млн человек [6], а на 01.01.2019 г. - уже 4,24 млн [7].

Кроме того, МС также ассоциируется с такими проявлениями, как снижение фильтрационной функции почек, микроальбуминурия, повышение жесткости артерий, гипертрофия миокарда левого желудочка, диастолическая дисфункция и другие. Причем многие из этих нарушений проявляются независимо от наличия АГ. МС в настоящее время рассматривается как предстадия атеросклероза и СД 2 типа [3]. Наличие МС повышает вероятность развития ишемического инсульта. Отдельные компоненты МС описываются более чем у 70\% больных, имеющих ишемический инсульт. У пациентов старческого возраста с ишемическим инсультом в сочетании с МС наблюдались значимое повышение частоты удлинения интервала Q-Т и более низкие показатели артериального давления, что влияет на возрастание риска гипоперфузионных осложнений и развитие фатальных аритмий у таких пациентов [8]. Также отдельные компоненты МС, такие как ожирение и СД 2 типа, ухудшают прогноз при хронической сердечной недостаточности [9] и течение острого периода инфаркта миокарда, увеличивая риск возникновения нарушений ритма [10].

В данной обзорной статье поиск информации проводился в базах данных PubMed и eLIBRARY за последние 10 лет по ключевым словам: ожирение, метаболический синдром, инсулинорезистентность, лептин, резистин, адипонектин, апелин.

\section{ОЖИРЕНИЕ И МЕТАБОЛИЧЕСКИЙ СИНДРОМ}

Частота МС часто совпадает с частотой ожирения и СД 2 типа, который является одним из компонентов MC [11]. Тем не менее ожирение не всегда является синонимом МС. Есть так называемые метаболически здоровые люди с ожирением, у которых достаточно высокий уровень чувствительности к инсулину и нет гипертонии, гиперлипидемии и других признаков МС. Эпидемиологические исследования показывают, что такие метаболически здоровые лица могут составлять значительную часть среди пациентов с ожирением [12]. Однако не существует единых критериев метаболически здорового ожирения (МЗО), в связи с чем частота его отличается в разных исследованиях. По данным М.А. Бояриновой и соавт. (2016), частота МЗО составляет от 12 до 35\% в зависимости от выбранных критериев. При этом отмечено, что с увеличением индекса массы тела (ИМТ) доля лиц с фенотипом МЗО снижалась по всем критериям. Это говорит о том, что данное состояние наиболее характерно для лиц с меньшей выраженностью ожирения. Хотя М3О отмечалось даже у пациентов с ожирением III степени [13]. Таким образом, изолированная оценка только ИМТ недостаточно информативна в плане прогноза метаболических нарушений и риска сердечно-сосудистых заболеваний.

В качестве дополнительных антропометрических параметров для оценки типа ожирения используют показатель окружности талии (ОТ). Отмечено, что этот показатель связан с неблагоприятными сердечно-сосудистыми событиями. У пациентов с фибрилляцией предсердий увеличение значения ОТ сопровождается увеличением размера левого предсердия и частоты гипертрофии левого желудочка, а также частоты пароксизмов [14].

Увеличение показателя ОТ свидетельствует о распределении жировой ткани по висцеральному (абдоминальному) типу. Именно этот тип ожирения является основным компонентом МС.

\section{КРИТЕРИИ МЕТАБОЛИЧЕСКОГО СИНДРОМА}

В настоящее время для постановки диагноза «метаболический синдром» необходим 1 основной критерий висцеральное ожирение (ОТ у женщин более 80 см и у мужчин более 94 см) и 2 дополнительных [1]:

- уровень АД >140 и 90 мм рт.ст. или лечение антигипертензивными препаратами;

- повышение уровня триглицеридов ( $\geq 1,7$ ммоль/л);

- снижение уровня холестерина липопротеинов высокой плотности (<1,0 ммоль/л у мужчин; <1,2 ммоль/л у женщин);

- повышение уровня холестерина липопротеинов низкой плотности >3,0 ммоль/л;

- нарушения углеводного обмена (нарушенная толерантность к глюкозе, или нарушение гликемии натощак, или СД 2 типа).

Связующим звеном всех указанных проявлений является ИР, которая посредством ряда механизмов повышает тонус сосудов, стимулирует пролиферацию гладкомышечных клеток сосудов, способствует развитию дислипидемии. Все это приводит к развитию сердечно-сосудистых заболеваний.

Висцеральное ожирение не случайно выделяют как основной критерий постановки диагноза МС. Именно оно является мощным фактором риска метаболических нарушений и приводит к развитию ИР и компенсаторной гиперинсулинемии. В организме человека существуют два вида белой жировой ткани: висцеральная и подкожная. Сами адипоциты, даже в пределах одной жировой подушки, также могут быть неоднородны по своей природе как генетически, так и метаболически [15-17]. Абдоминальный жир имеет некоторые особенности, которые приводят к формированию ИР, в то время как накопление подкожного жира, напротив, не приводит к метаболическим нарушениям и может даже быть защитным от МС $[18,19]$. При абдоминальном - метаболически неблагополучном варианте ожирения наблюдаются гипертрофия адипоцитов висцеральной жировой ткани и ее инфильтрация макрофагами и лимфоцитами с увеличением синтеза провоспалительных цитокинов, а также ряда вазоконстрикторных и прокоагуляционных соединений, вносящих вклад в формирование дисфункции эндотелия и последующее ремоделирование сердечно-сосудистой системы. Кроме того, в гипертрофированных адипоцитах происходит усиленный липолиз, который приводит к массивному поступлению свободных жирных кислот в кровоток, эктопическому депонированию жира, хроническому воспалению и ИР [20]. Абдоминальный жир является гормонально активным. Известно, что висцеральная жировая ткань вырабатывает множество различных биологически активных веществ, которые получили название адипокинов. Эти адипокины играют важную роль в формировании ИР. 
Тот факт, что патологическое изменение содержания адипокинов при МС обусловлено именно ожирением, а не другими компонентами MC, подтверждают результаты исследования Farooq R. et al. (2017). Авторами обнаружены более выраженные нарушения уровней лептина, резистина и адипонектина у пациентов с ожирением по сравнению с пациентами, имеющими только СД 2 типа [21].

Многочисленные исследования последних лет позволили выдвинуть гипотезу, что адипокины - лептин, резистин, адипонектин и другие - являются возможным связующим звеном между ожирением и другими компонентами МС и могут способствовать возникновению таких ассоциированных с ожирением проблем, как дислипидемия, ИР и атеросклероз. Высокая частота сердечно-сосудистых заболеваний при МС и ее сочетания с висцеральным ожирением также может быть связана с изменением секреции адипокинов. Кроме того, нарушение выработки этих адипокинов избыточным количеством висцерального жира способствует провоспалительному состоянию [22].

\section{лептИн}

Этот адипокин является одним из наиболее изученных. В настоящее время общеизвестной является связь гиперлептинемии с ожирением. Это подтверждают исследования как отечественных, так и зарубежных авторов [23-25]. При ожирении отмечаются более высокие уровни лептина по сравнению с лицами без ожирения, причем содержание этого адипокина прямо коррелирует с выраженностью ожирения и ИМТ как у мужчин, так и у женщин [23-25], а также с гипертрофией подкожных адипоцитов [26].

Основная роль лептина в организме - контроль потребления пищи. При этом от режима и характера питания содержание этого адипокина тоже зависит: при потреблении пищи, богатой жирами, уровень лептина увеличивается, а уменьшается - при голодании [27] и применении омега-3-полиненасыщенных жирных кислот [28]. Ранее было обнаружено, что мыши и люди, имеющие мутации лептина и его рецепторов, страдают гиперфагией и выраженным ожирением [29, 30]. Лечение рекомбинантным лептином в этом случае приводило к улучшению состояния. Однако при других формах ожирения эффект лептина снижен, что указывает на резистентность к этому адипокину больных ожирением [30, 31]. Одним из факторов, влияющих на центральную резистентность к лептину, является аутосупрессия, посредством которой лептин стимулирует экспрессию супрессора передачи сигналов цитокинов-3 (SOCS-3), который ингибирует передачу сигналов лептина. Повышенная экспрессия SOCS-3 в ответ на лептин может быть основной причиной нечувствительности к лептину [27].

Позже было выявлено, что стресс влияет на секрецию лептина. В исследованиях на животных обнаружено, что в группах «Стресс» и «Ожирение+стресс» уровень лептина достоверно снижался, при этом в группе «Ожирение» его уровень был повышенным. Авторы считают, что сниженное содержание лептина в крови при хроническом стрессе может быть фактором, приводящим к нарушению пищевого поведения [32].

Помимо связи с ИМТ, наблюдаются также ассоциации гиперлептинемии с резистентностью к инсулину и гиперинсулинемией $[24,33]$, что позволяет предположить, что высокое содержание лептина является предиктором развития ИР и других метаболических нарушений у пациентов с ожирением [24]. Так, гиперлептинемия наблюдается при СД 2 типа и вносит вклад в развитие этого заболевания [34, 35]. Использование лептина в качестве терапевтической мишени при лечении СД 2 типа в настоящее время обсуждается. Отмечено, что снижение этого адипокина происходит в результате применения ингибиторов SGLT-2 [36].

Лептин вносит определенный вклад в развитие АГ. Отмечается его более высокий уровень у пациентов с АГ по сравнению с нормотензивными лицами [33, 37]. Возможно, это связано с тем, что лептин может увеличивать избыточную жесткость сосудов, внося вклад в патогенез АГ и поражение органов-мишеней [38]. У женщин с АГ и ожирением отмечен рост уровня лептина по мере увеличения степени диастолической дисфункции левого желудочка [39]. Кроме того, гиперлептинемия уже у молодых пациентов с ожирением оказывает влияние на ремоделирование миокарда [23].

Лептин связан и с другими сердечно-сосудистыми заболеваниями. Отмечена связь высоких уровней лептина с частотой пароксизмов у пациентов с фибрилляцией предсердий: гиперлептинемия более 8,7 мг/мл и ОТ более 80 см увеличивали риск повторных пароксизмов. Также авторами отмечено, что в группе пациентов с повторными пароксизмами уровень лептина был выше, чем в пациентов без них [14]. У пациентов с острым инфарктом миокарда концентрация лептина была прямо связана с уровнем тропонинов. Авторы рассматривают гиперлептинемию как дополнительный фактор постинфарктного ремоделирования миокарда [40].

Таким образом, лептин является адипокином, который оказывает влияние на развитие ИР, нарушений углеводного обмена, АГ и тем самым вносит существенный вклад в формирование MC.

\section{АДИПОНЕКТИН}

Этот секретируемый адипоцитами пептид является основным связующим звеном между ожирением, ИР и воспалением [41].

Основными рецепторами к адипонектину являются AdipoR-1 и AdipoR-2. AdipoR-1 располагается в основном в мышечной ткани, коже и подкожной жировой клетчатке. Он имеет сродство в большей степени к глобулярному домену адипонектина и в меньшей степени - к целой молекуле этого адипокина. AdipoR-2 расположен в печени и может связываться как с целой молекулой адипонектина, так и с расщепленной $[41,42]$. Ген адипонектина локализуется на участке хромосомы 3q27. Данный участок ассоциируется с высоким риском развития ожирения и неблагоприятным метаболическим фенотипом [43]. Была показана связь мутаций и полиморфных вариантов этого гена с различными метаболическими отклонениями, а также с риском кардиоваскулярной патологии. Так, например, в популяции арабов Туниса обнаружена значимая связь 6 полиморфизмов гена $A D I P O Q$ с развитием СД 2 типа [44].

Адипонектин является одним из немногих адипокинов, оказывающих положительное влияние на метаболизм. Он обладает антиатерогенным и кардиопротективным действиями. Этот гормон увеличивает 
чувствительность к инсулину, а также выживаемость и функциональность бета-клеток поджелудочной железы. Адипонектин снижает ИР через два атипичных семимембранных рецептора. В мышцах адипонектин действует через AdipoR1, активируя 5'AMФ-активируемую протеинкиназу (AMPK); в печени адипонектин действует как на AdipoR1, так и на AdipoR2, подавляя выработку глюкозы в печени $[45,46]$.

Адипонектин оказывает непосредственное положительное влияние на жировую ткань: приводит к увеличению плотности митохондрий, уменьшению размера адипоцитов и усилению транскрипции факторов, связанных с эффективной этерификацией свободных жирных кислот. Также этот адипокин оказывает защитное действие в отношении развития МС, что было показано в опытах на мышах с синдромом поликистозных яичников [47].

Протективное действие адипонектина на метаболизм и чувствительность к инсулину объясняется его противовоспалительным действием. В этом случае эффект адипонектина противоположен лептину. Лептин повышает концентрацию воспалительных адипокинов: фактора некроза опухоли-а и интерлейкина-6, усиливая ИР и увеличивая риск развития СД 2 типа. Адипонектин, напротив, снижает экспрессию и высвобождение этих медиаторов воспаления и предотвращает развитие метаболических расстройств [48-50]. В связи с этим лептин и адипонектин могут быть маркерами активности воспалительного процесса в жировой ткани и использоваться при прогнозировании развития и тяжести метаболических нарушений при различных заболеваниях [51]. Так, например, повышение уровня лептина у больных бронхиальной астмой может служить фактором риска развития нарушений углеводного обмена, а снижение уровня адипонектина - фактором прогрессирования дислипидемии [51].

Снижение уровня адипонектина связано с развитием ряда заболеваний: ожирения, атеросклероза, ишемической болезни сердца и СД 2 типа $[41,21]$. Отечественными и зарубежными авторами продемонстрировано значимое снижение содержания адипонектина при ожирении и СД 2 типа, а также связь гипоадипонектинемии с ИР [25, 34, 52-54]. Предполагается, что уровни адипонектина в сыворотке крови могут быть независимым фактором риска прогрессирования предиабета и развития СД 2 типа [53], а также маркером ИР [54]. Хотя, по некоторым данным, гипоадипонектинемия, наблюдаемая при ожирении, не участвует в развитии СД 2 типа. Авторы делают такой вывод после обследования подростков с СД 2 типа, так как уровни адипонектина не различались у подростков с ожирением в сочетании с СД 2 типа и без диабета [55].

Свое кардиопротективное действие адипонектин оказывает также посредством стимуляции фосфорилирования и активации АМФ(аденозинмонофосфат)-киназы, оказывая при этом прямое воздействие на эндотелий сосудов, уменьшая воспалительную реакцию на механическое повреждение и усиливая защиту эндотелия в случаях дефицита аполипопротеина E [41]. Кроме того, адипонектин оказывает значимое влияние на липидный обмен. Он повышает уровень липопротеинов высокой плотности и снижает уровень триглицеридов. Имеются данные об ассоциации низкого уровня адипонектина с нарушениями липидного обмена у лиц с ожирением и СД 2 типа [34, 52], что свидетельствует об антиатерогенном действии этого адипокина [51].

Гипоадипонектинемия, напротив, связана с развитием кардиоваскулярной патологии и повышением сердечно-сосудистого риска. Так, согласно данным Л.В. Родионовой (2017), у пациентов с АГ содержание адипонектина значимо ниже, чем у пациентов без АГ [37]. Кроме того, авторы выявили обратную ассоциацию между содержанием адипонектина и курением. То есть имеется зависимость между интенсивностью курения и утратой способности жировой ткани к синтезу такого кардиопротективного адипокина, как адипонектин [37], что вносит определенный вклад в повышение кардиоваскулярного риска у курящих пациентов. Отмечено, что концентрация адипонектина при остром инфаркте миокарда обратно связана с уровнем тропонинов в крови. Возможно, защитные свойства этого адипокина уменьшаются при тяжелом, распространенном инфаркте миокарда. Также в остром периоде инфаркта миокарда отмечена обратная ассоциация адипонектина с индексом HOMA-IR и уровнем глюкозы [40]. Гипоадипонектинемия связана с диастолической дисфункцией, которая довольно часто наблюдается при ожирении. По данным Н.Н. Кириченко (2019), развитие диастолической функции сопровождается снижением адипонектина [39].

Таким образом, гипоадипонектинемия имеет негативные последствия в отношении развития МС и связанных с ним нарушений, а также сердечно-сосудистых заболеваний. Кроме того, более высокое содержание адипонектина связано с лучшим гликемическим контролем. Возможно, терапевтические меры, направленные на повышение его уровня, будут полезны для улучшения контроля СД 2 типа [54]. Повысить содержание этого адипокина можно путем коррекции образа жизни. Концентрация адипонектина у пациентов с ожирением повышается за счет снижения веса как у пациентов с СД 2 типа, так и без него, а также сопровождается снижением провоспалительных факторов. Изменение характера питания, такое как потребление рыбы, употребление добавок омега-3-полиненасыщенных жирных кислот [28], соблюдение средиземноморской диеты и потребление кофе, способствуют повышению уровня адипонектина. Ряд препаратов оказывает влияние на увеличение уровня этого гормона. К ним относятся: глимепирид [21], глитазоны и производные фиброевой кислоты (фенофибрат) [41], ингибиторы SGLT-2 [36]. Антигипертензивные препараты также могут повышать содержание адипонектина. К таким препаратам относятся ингибиторы ангиотензинпревращающего фермента (АПФ) и блокаторы рецепторов ангиотензина (БРА) [41]. Не все препараты имеют одинаковый эффект в отношении роста уровня этого адипокина. Так, например, азилсартан медоксомил вызывал более значимое повышение адипонектина по сравнению с другими БРА (лозартаном, валсартаном и телмисартаном), а также ингибиторами АПФ [56, 57].

\section{РЕЗИСТИН}

Свое название он получил за способность вызывать ИР у мышей, у которых он вырабатывается адипоцитами висцеральной жировой ткани. У человека в некоторых работах также было показано прогностическое 
значение резистина в отношении СД 2 типа $[58,59]$ и его повышение при ожирении и диабете [33, 34]. Однако нет однозначного мнения в отношении механизмов такого влияния. У людей резистин вырабатывается макрофагами, что позволяет предположить, что этот гормон и его эффекты связаны с воспалением $[60,61]$. Есть данные, что олигомерная форма резистина у людей стимулирует выработку провоспалительных цитокинов [62].

В ряде исследований была продемонстрирована ассоциация резистина с кардиоваскулярной патологией. Показано, что у пациентов с СД 2 типа резистин является предиктором серьезных сердечно-сосудистых событий и смертности от всех причин [63]. Резистин участвует в процессе развития атеросклероза [64]. Это происходит посредством влияния на эндотелий сосудов. Он увеличивает пролиферацию и миграцию эндотелиальных и гладкомышечных клеток сосудов и увеличивает проницаемость эндотелия [65]. Это подтверждается тем, что уровень резистина связан с рецидивирующими коронарными событиями у пациентов после госпитализации по поводу острого коронарного синдрома [66]. Аналогичные результаты получены и отечественными авторами. В исследовании А.З. Авсараговой (2019) показано, что гиперрезистинемия более 8,5 нг/мл является фактором риска развития сердечно-сосудистых осложнений в отдаленном периоде после перенесенного острого коронарного синдрома, сопровождавшегося стентированием [67].

Некоторые клинические исследования показали, что уровни циркулирующего резистина связаны с АГ [68]. Отмечено, что содержание резистина выше у пациентов с АГ. При этом уровень этого адипокина увеличивался при наличии такого фактора сердечно-сосудистого риска, как курение. Этот феномен наблюдался не только у лиц с АГ, но и у курящих контрольной группы [37]. Также резистин участвует в ремоделировании миокарда у молодых пациентов с ожирением [23].

Таким образом, несмотря на неоднозначность роли резистина в развитии ИР, исследования последних лет показали связь этого адипокина с отдельными компонентами МС: ожирением, СД 2 типа, АГ, а также сердечно-сосудистыми заболеваниями.

\section{АПЕЛИН}

Этот адипокин является относительно малоизученным. Отмечено, что его уровень увеличивается при ожирении и связан непосредственно с висцеральным типом распределения жировой ткани. Обнаружено, что концентрация апелина плазмы достоверно повышается при увеличении степени абдоминального ожирения и при этом прямо коррелирует с ОТ и отношением ОТ к окружности бедер (ОТ/ОБ) [69]. Высокое содержание апелина зарегистрировано также при ожирении в сочетании с гиперинсулинемией [70]. Повышение уровня этого пептида при СД 2 типа отмечено в нескольких исследованиях [71-73]. Причем Habchi M. et al. (2014) продемонстрировали повышение уровня апелина при СД как 1, так и 2 типа. При этом рост уровня апелина при СД 1 типа был выше, чем при СД 2 типа. Это может свидетельствовать о том, что содержание апелина определяется не только наличием ожирения. Также показано, что у пациентов с СД 2 типа данный адипокин отрицательно коррелирует с уровнем гликозилированного гемоглобина. Это может указывать на участие апелина в гликемическом балансе и его влияние на чувствительность к инсулину [71].

Помимо влияния на углеводный обмен, апелин вносит определенный вклад в развитие АГ. Так, уровень этого гормона при ожирении ниже у лиц с АГ по сравнению с нормотензивными пациентами. Концентрация апелина изменяется в зависимости от степени АГ. В исследовании А.В. Федоровой, Т.Н. Пановой (2015) концентрация апелина в плазме была выше при 2 степени АГ по сравнению 1 степенью, однако при 3 степени она снижалась. Вероятно, это объясняется срывом защитных механизмов [74]. Аналогичные результаты получили С.М. Коваль, К.О. Юшко (2014). Авторы показали снижение уровня апелина у пациентов с сочетанием АГ и СД 2 типа по сравнению с группой пациентов без АГ. При этом выраженность снижения уровня апелина ассоциировалась с продолжительностью гипертензии и величиной диастолического артериального давления. Возможно, это свидетельствует об истощении продукции этого адипокина при длительном течении заболевания. Зависимость уровня апелина от величины диастолического артериального давления, по мнению авторов, свидетельствует о наличии у этого пептида вазодилатационного эффекта [75]. По данным метаанализа, снижение уровня циркулирующего апелина в значительной степени связано с повышенным риском АГ [76].

\section{ЗАКЛЮЧЕНИЕ}

Патогенез MC сложен и не до конца ясен. Тем не менее можно утверждать, что гормональная активность абдоминальной жировой ткани играет важную роль в развитии главного связующего звена всех компонентов МC - резистентности к инсулину. Помимо этого, адипокины участвуют в формировании и других компонентов этого симптомокомплекса - АГ, СД 2 типа и дислипидемии. Эти данные свидетельствуют о перспективности терапевтического воздействия на гормоны жировой ткани с целью уменьшения метаболических нарушений. В настоящее время обнаружено влияние некоторых препаратов на уровни лептина и адипонектина. Однако алгоритмов использования адипокинов в качестве терапевтических целей на данный момент не сформировано, что требует дополнительных исследований.

\section{ДОПОЛНИТЕЛЬНАЯ ИНФОРМАЦИЯ}

Источники финансирования. Работа выполнена по инициативе авторов без привлечения финансирования.

Конфликт интересов. Авторы декларируют отсутствие явных и потенциальных конфликтов интересов, связанных с содержанием настоящей статьи.

Участие авторов. Вербовой А.Ф. - существенный вклад в концепцию статьи, написание статьи; Вербовая Н.И. - существенный вклад в концепцию статьи и внесение в рукопись существенных правок с целью повышения научной ценности статьи; Долгих Ю.А. - анализ данных и написание статьи. Все авторы одобрили финальную версию статьи перед публикацией, выразили согласие нести ответственность за все аспекты работы, подразумевающую надлежащее изучение и решение вопросов, связанных с точностью или добросовестностью любой части работы. 


\section{СПИСОК ЛИТЕРАТУРЫ | REFERENCES}

1. Оганов Р.Г., Симаненков В.И., Бакулин И.Г., и др. Коморбидная патология в клинической практике. Алгоритмы диагностики и лечения // Кардиоваскулярная терапия и профилактика. - 2019. - Т. 18. - №1. - С. 5-66. [Oganov RG, Simanenkov VI, Bakulin IG, et al. Comorbid pathology in clinical practice. Diagnostic and treatment algorithms. Cardiovascular Therapy and Prevention. 2019;18(1):5-66. (In Russ.)]. doi: https://doi.org/10.15829/1728-8800-2019-1-5-66.

2. Hanefeld M, Leonhardt W. Das metabolische Syndrom. Dtsch Gesundh Wesen. 1981;36: 545-551.

3. Рекомендации по ведению больных с метаболическим синдромом. Клинические рекомендации МЗ РФ. 2013. 43 с. [Recommendations for the management of patients with metabolic syndrome. Clinical guidelines Ministry of Health of the Russian Federation. 2013. 43 p. (In Russ.)]. Доступно по: https://mzdrav. rk.gov.ru/file/mzdrav_18042014_Klinicheskie_rekomendacii_ Metabolicheskij_sindrom.pdf. Ссылка активна на 09.12.2020.

4. Бадин Ю.В., Фомин И.В., Беленков Ю.Н., и др. ЭПОХА-АГ 1998-2017 гг:. динамика распространенности, информированности об артериальной гипертонии, охвате терапией и эффективного контроля артериального давления в европейской части РФ // Кардиология. - 2019. - Т. 59. — №1S. - С. 34-42. [Badin YuV, Fomin IV, Belenkov YuN, et al. EPOCHA-AH 1998-2017. Dynamics of prevalence, awareness of arterial hypertension, treatment coverage, and effective control of blood pressure in the European part of the Russian Federation. Kardiologiya. 2019;59(1S):34-42. (In Russ.)]. doi: https://doi.org/10.18087/cardio.2445

5. Дедов И.И., Шестакова М.В., Викулова О.К., и др. Атлас регистра сахарного диабета Российской Федерации. Статус 2018 г. // Сахарный диабет. - 2019. - Т. 22. - №52-2. - C. 4-61. [Dedov II, Shestakova MV, Vikulova OK, et al. Atlas of diabetes register in Russian Federation, status 2018. Diabetes mellitus. 2019;22(S2-2):4-61. (In Russ.)]. doi: https://doi.org/10.14341/DM12208

6. Дедов И.И., Шестакова М.В., Викулова О.К., и др. Сахарный диабет в Российской Федерации: распространенность, заболеваемость, смертность, параметры углеводного обмена и структура сахароснижающей терапии по данным Федерального регистра сахарного диабета, статус 2017 г. // Сахарный диабет. — 2018. T. 21. - №3. - C. 144-159. [Dedov II, Shestakova MV, Vikulova OK, et al. Diabetes mellitus in Russian Federation: prevalence, morbidity, mortality, parameters of glycaemic control and structure of glucose lowering therapy according to the Federal Diabetes Register, status 2017. Diabetes mellitus. 2018;21(3):144-159. (In Russ.)]. doi: https://doi.org/10.14341/DM9686

7. Шестакова М.В., Викулова О.К., Железнякова А.В., и др. Эпидемиология сахарного диабета в Российской Федерации: что изменилось за последние десятилетия? // терапевтический архив. — 2019. — Т. 91. — №10. C. 4-13 [Shestakova MV, Vikulova OK, Zheleznyakova AV, et al. Diabetes epidemiology in Russia: what has changed over the decade? Therapeutic Archive. 2019;91(10):4-13. (in Russ.)]. doi: https://doi.org/10.26442/00403660.2019.10.000364

8. Басанцова Н.Ю., Тибекина Л.М., Шишкин А.Н. Особенности сердечно-сосудистой регуляции у пациентов разного возраста в остром периоде ишемического инсульта на фоне метаболического синдрома // Здоровье — основа человеческого потенциала: проблемы и пути их решения. 2018. — T. 13. — №1. - C.218-223. [Basantsova NYu., Tibekina LM., Shishkin AN. Features of cardiovascular regulation in patients of different ages in the acute period of ischemic stroke against the background of metabolic syndrome. Zdorov'ye - osnova chelovecheskogo potentsiala: problemy i puti ikh resheniya. 2018;13(1):218-223. (In Russ.)].

9. Краием Н., Поляков Д.С., Фомин И.В., и др. Динамика распространенности хронической сердечной недостаточности и сахарного диабета в Нижегородской области с 2000 по 2017 год // Кардиология. - 2018. - Т. 58. - №2S. - C. 25-32. [Kraiem N, Polyakov DS, Fomin IV, et al. Time-related changes in prevalence of chronic heart failure and diabetes mellitus in Nizhny Novgorod Region between 2000 and 2017. Kardiologiia. 2018;58(2S):25-32. (In Russ.)]. doi: https://doi.org/10.18087/cardio.2439

10. Главатских К.Ю., Лукьянова И.Ю., Шальнев В.И., Пчелин И.Ю. Влияние коморбидной нагрузки на клиническое течение нижнего инфаркта миокарда с поражением правого желудочка // Скорая медицинская помощь. - 2019. - T. 20. — №4. - C.63-70. [Glavatskikh KYu, Lukyanova IYu, Shalnev VI, Pchelin IYu. Impact of comborbide load on clinical course of inferior wall myocardial infarction with right ventricular involvement. Emergency medical care. 2019;20(4):63-70. (In Russ.)]. doi: https://doi.org/10.24884/2072-6716-2019-20-4-63-70

11. Saklayen MG. The Global Epidemic of the Metabolic Syndrome. Curr Hypertens Rep. 2018;20(2):12. doi: https://doi.org/10.1007/s11906-018-0812-z

12. Wildman RP, Muntner P, Reynolds K, et al. The obese without cardiometabolic risk factor clustering and the normal weight with cardiometabolic risk factor clustering: prevalence and correlates of 2 phenotypes among the US population (NHANES 1999-2004). Arch Int Med. 2008;168:1617-1624 doi: https://doi.org/10.1001/archinte.168.15.1617

13. Бояринова М.А., Орлов А.В., Ротарь О.П., и др. Адипокины и метаболически здоровое ожирение у жителей Санкт-Петербурга (в рамках эпидемиологического исследования ЭССЕ-РФ) // Кардиология. - 2016. - Т. 56. - №8. - C. 40-45. [Boyarinova MA, Orlov AV, Rotar'OP, et al. Adipokines Level in Metabolically Healthy Obese Saint-Petersburg Inhabitants (ESSE-RF). Kardiologiia. 2016;56(8):40-45. (In Russ.)]. doi: https://doi.org/10.18565/cardio.2016.8.40-45

14. Рябая И.Н., Сердечная Е.В. Фибрилляция предсердий у пациентов с ожирением в практике терапевта // Курский научнопрактический вестник «Человек и его здоровье». - 2018. T. 1. - C. 30-35. [Ryabaya IN, Serdechnaya EV. Atrial fibrillation in obese patients in therapeutic practice. Kursk Scientific and Practical Bulletin «Man and His Health». 2018;(1):30-35. (In Russ.)]. doi: https://doi.org/10.21626/vestnik/2018-1/05

15. Varlamov O, Chu M, Cornea A, et al. Cell-autonomous heterogeneity of nutrient uptake in white adipose tissue of rhesus macaques. Endocrinology. 2015;156(1):80-89. doi: https://doi.org/10.1210/en.2014-1699

16. Lee KY, Sharma R, Gase G, et al. Tbx15 defines a glycolytic subpopulation and white adipocyte heterogeneity. Diabetes. 2017;66(11):2822-2829. doi: https://doi.org/10.2337/db17-0218

17. Hagberg CE, Li Q, Kutschke M, et al. Flow cytometry of mouse and human adipocytes for the analysis of browning and cellular heterogeneity. Cell Rep. 2018;24(10):2746-2756.e5. doi: https://doi.org/10.1016/j.celrep.2018.08.006

18. Ghaben AL, Scherer PE. Adipogenesis and metabolic health. Nat Rev Mol Cell Biol. 2019;20(4):242-258. doi: https://doi.org/10.1038/s41580-018-0093-z

19. Fox CS, Massaro JM, Hoffmann U, et al. Abdominal visceral and subcutaneous adipose tissue compartments: association with metabolic risk factors in the Framingham Heart Study. Circulation. 2007;1 16(1):39-48. doi: https://doi.org/10.1161/circulationaha.106.675355

20. Hammarstedt A, Gogg S, Hedjazifar S, et al. Impaired Adipogenesis and Dysfunctional Adipose Tissue in Human Hypertrophic Obesity. Physiol Rev. 2018;98(4):1911-1941. doi: https://doi.org/10.1152/physrev.00034.2017

21. Farooq R, Amin S, Hayat Bhat M, et al. Type 2 diabetes and metabolic syndrome - adipokine levels and effect of drugs. Gynecol Endocrinol. 2017;33(1):75-78. doi: https://doi.org/10.1080/09513590.2016.1207165

22. Kumari R, Kumar S, Kant R. An update on metabolic syndrome: Metabolic risk markers and adipokines in the development of metabolic syndrome. Diabetes Metab Syndr. 2019;13(4):2409-2417. doi: https://doi.org/10.1016/j.dsx.2019.06.005

23. Долгих Ю.А., Вербовой А.Ф., Митрошина Е.В. Оценка гормональнометаболических показателей и состояния сердечно-сосудистой системы при ожирении, манифестировавшем в пубертатный период у юноше // Справочник врача общей практики. 2013. - T. 1. - C. 041-049. [Dolgikh YuA, Verbovoy AF, Mitroshina YeV. Assessment of hormonal and metabolic parameters and the state of the cardiovascular system in obesity, manifested in adolescence in young men. Spravochnik vracha obshchey praktiki. 2013;1:041-049. (In Russ.)].

24. Martins Mdo C, Lima Faleiro L, Fonseca A. Relação entre a leptina, a massa corporal e a síndrome metabólica numa amostra da população adulta [Relationship between leptin and body mass and metabolic syndrome in an adult population]. Rev Port Cardiol. 2012;31(11):711-719. doi: https://doi.org/10.1016/j.repc.2012.08.002 
25. Liu W, Zhou X, LiY, et al. Serum leptin, resistin, and adiponectin levels in obese and non-obese patients with newly diagnosed type 2 diabetes mellitus: A population-based study. Medicine (Baltimore). 2020;99(6):e19052. doi: https://doi.org/10.1097/MD.0000000000019052

26. Климонтов В.В., Булумбаева Д.М., Бгатова Н.П., и др. Концентрации адипокинов в сыворотке крови у пациентов с сахарным диабетом 2 типа: взаимосвязи с распределением, гипертрофией и васкуляризацией подкожной жировой ткани // Сахарный диабет. - 2019. - T. 22. — №4. — C. 336-347. [Klimontov V, Bulumbaeva DM, Bgatova NP, et al. Serum adipokine concentrations in patients with type 2 diabetes: the relationships with distribution, hypertrophy and vascularization of subcutaneous adipose tissue. Diabetes Mellitus. 2019;22(4):336-347. (In Russ.)]. doi: https://doi.org/10.14341/DM10129

27. Zieba DA, Biernat W, Barć J. Roles of leptin and resistin in metabolism, reproduction, and leptin resistance. Domest Anim Endocrinol. 2020:73:106472. doi: https://doi.org/10.1016/j.domaniend.2020.106472

28. Farimani AR, Hariri M, Azimi-Nezhad M, et al. The effect of $n-3$ PUFAs on circulating adiponectin and leptin in patients with type 2 diabetes mellitus: a systematic review and meta-analysis of randomized controlled trials. Acta Diabetol. 2018;55(7):641-652. doi: https://doi.org/10.1007/s00592-018-1110-6

29. Friedman JM. The function of leptin in nutrition, weight, and physiology. Nutr Rev. 2002;60(10 pt 2):S1-S14. doi: https://doi.org/10.1301/002966402320634878

30. Farooqi IS, O'Rahilly S. 20 years of leptin: human disorders of leptin action. J Endocrinol. 2014;223(1):T63-T70. doi: https://doi.org/10.1530/joe-14-0480

31. Flier JS. Hormone resistance in diabetes and obesity: insulin, leptin and FGF21. Yale J Biol Med. 2012;85(3):405-414

32. Калиновская Е.И., Кондрашова С.Б., Полулях О.Е., и др. Стрессиндуцированные изменения уровня адипокинов в сыворотке крови крыс с алиментарным ожирением // Вес. Нац. акад. наук Беларусі. Сер. мед. навук. - 2017. - Т. 2. - С. 71-77. [Kalinovskaya El, Kondrashova SB, Poluliakh OE, et al. Stress-induced changes in the level of adipokines in the blood serum of rats with alimentary obesity. Proceedings of the National Academy of Sciences of Belarus, medical series. 2017;2:71-77. (In Russ.)]

33. Вербовой А.Ф., Митрошина Е.В., Долгих Ю.А. Адипокины, инсулинорезистентность и активность симпато-адреналовой системы у юношей с ожирением, манифестировавшим в пубертатный период // Ожирение и метаболизм. - 2012. T. 9. - №2. - C. 49-52. [Verbovoy AF, Mitroshina EV, Dolgih YuA. Adipokines, insulin resistance and activity of the sympathoadrenal system in young men with adolescent obesity. Obesity and Metabolism. 2012:9(2):49-52. (In Russ.)].

34. Вербовой А.Ф., Цанава И.А., Вербовая Н.И. Адипокинь и метаболические показатели у больных сахарным диабетом 2 типа в сочетании с подагрой // Ожирение и метаболизм. 2016. - T. 3. - №1. - C. 20-24. [Verbovoy AF, Tsanava IA, Verbovaya NI. Adipokines and metabolic parameters in patients with type 2 diabetes mellitus in combination with gout. Obesity and Metabolism. 2016;3(1):20-24. (In Russ.)]. doi: https://doi.org/10.14341/omet2016120-24

35. Ghadge AA, Khaire AA. Leptin as a predictive marke for metabolic syndrome. Cytokine. 2019;121:154735. doi: https://doi.org/10.1016/j.cyto.2019.154735

36. Wu P, Wen W, Li J, et al. Systematic Review and Meta-Analysi of Randomized Controlled Trials on the Effect of SGLT2 Inhibitor on Blood Leptin and Adiponectin Level in Patients with Type 2 Diabetes. Horm Metab Res. 2019;51 (8):487-494. doi: https://doi.org/10.1055/a-0958-2441

37. Родионова Л.В., Плехова Н.Г., Богданов Д.Ю., Захарчук Н.В. Содержание адипокинов в сыворотке крови у лиц различного сердечно-сосудистого риска // Тихоокеанский медииинский журнал. - 2017. - №4. - C. 77-82. [Rodionova LV, Plechova NG, Bogdanov DY, Zaharchuk NV. The serum levels of adipokines in individuals with different cardiovascular risk. Pacific Medical Journal. 2017;4(70):77-82. (In Russ.)] doi: https://doi.org/10.17238/pmj1609-1175.2017.4.77-82

38. Sakovskaia A, Nevzorova V, Brodskaya T, Chkalovec I. Condition aortic stiffness and content of adipokines in the serum of patients with essential hypertension in young and middle-aged. Journal of Hypertension. 2015;33(I-1):182. doi: https://doi.org/10.1097/01.hjh.0000467889.58341.7c
39. Кириченко Н.Н. Особенности обмена адипокинов у женщин с артериальной гипертензией и ожирением в зависимости от состояния диастолической функции левого желудочка // Семейная медииина. - 2019. - Т. 5-6. — №85. - C. 87-90. [Kyrychenko NM. Features of adipokines metabolism in women with arterial hypertension and obesity, depending on the left ventricular diastolic function. Semeynaya meditsina. 2019;5-6(85):87-90. (In Russ.)]. doi: https://doi.org/10.30841/2307-5112.5-6.2019.194133

40. Матееску К.А., Лебедев П.А., Щербакова Н.Ф. Участие адипокинов в каскаде воспалительных и метаболических реакций в динамике острого инфаркта миокарда с подъемом ST // Аспирантский вестник Поволжья. - 2016. - Т. 16. — №1-2. C. 190-195. [Mateesku KA, Lebedev PA, Scherbakova NF. Implication of adipokines in the cascade of inflammatory and metabolic reactions in the dynamics of st elevation myocardial infarction. Aspirantskiy Vestnik Povolzhiya. 2016;16(1-2):190-195. (In Russ.)] doi https://doi.org/10.17816/2072-2354.2016.0.1-2.190-195

41. Fisman EZ, Tenenbaum A. Adiponectin: a manifold therapeutic target for metabolic syndrome, diabetes, and coronary disease? Cardiovasc Diabetol. 2014;13:103. doi: https://doi.org/10.1186/1475-2840-13-103

42. Hug C, J. Wang NS, Ahmad NS, et al. T-cadherin is a receptor for hexameric and high-molecular-weight forms of Acrp30/ adiponectin. Proc. Natl. Acad. Sci. USA. 2004;101(28):10308-10313. doi: https://doi.org/10.1073/pnas.0403382101

43. Kubota N, Yano W, Kubota T, et al. Adiponectin stimulates AMP-activated protein kinase in the hypothalamus and increases food intake. Cell Metab. 2007;6(1):55-68. doi: https://doi.org/10.1016/j.cmet.2007.06.003

44. Chaieb A, Mahjoub T, Almawi WY. Single-nucleotide polymorphisms and haplotypes in the adiponectin gene contribute to the genetic risk for type 2 diabetes in Tunisian Arabs. Diabetes Res Clin Pract. 2012;97(2):290-297. doi: https://doi.org/10.1016/j.diabres.2012.02.015

45. Okada-Iwabu M, Iwabu M, Yamauchi T, Kadowaki T. Structure and function analysis of adiponectin receptors toward development of novel antidiabetic agents promoting healthy longevity. Endocr J. 2018;65(10):971-977. doi: https://doi.org/10.1507/endocrj.ej18-0310

46. Turer AT, Scherer PE. Adiponectin: mechanistic insights and clinical implications. Diabetologia. 2012;55(9):2319-2326. doi: https://doi.org/10.1007/s00125-012-2598-x

47. Benrick A, Chanclón B, Micallef P, et al. Adiponectin protects against development of metabolic disturbances in a PCOS mouse model. Proc Natl Acad Sci USA. 2017;114(34):E7187-E7196. doi: https://doi.org/10.1073/pnas.1708854114

48. Whitehead JP, Richards AA, Hickman IJ, et al. Adiponectin a key adipokine in the metabolic syndrome. Diabetes Obes Metab. 2006;8(3):264-280. doi: https://doi.org/10.1111/j.1463-1326.2005.00510.x

49. Brocker C, Thompson D, Matsumoto A, et al. Evolutionary divergence and functions of human interleukin (IL) gene family. Hum Genomics. 2010:5(1):30-55. doi: https://doi.org/10.1186/1479-7364-5-1-30

50. Katagiri H, Yamada T, Oka Y. Adiposity and cardiovascular disorders: disturbance of the regulatory system consisting of humoral and neuronal signals. Circ Res. 2007;101(1):27-39. doi: https://doi.org/10.1161/circresaha.107.151621

51. Кузьмина Л.П., Хотулева А.Г. Адипокины как маркеры метаболических нарушений при профессиональной бронхиальной астме // Международный научно-исследовательский журнал. - 2016. T. 12-5. — №54. — C. 100-102. [Kuzmina LP, Khotuleva AG. Adipokines as markers of metabolic disorders in occupational asthma. Mezhdunarodnyy nauchno-issledovatel'skiy zhurnal. 2016;12-5(54):100-102. (in Russ.)]. doi: https://doi.org/10.18454/IRJ.2016.54.143

52. Митрошина Е.В. Взаимосвязь уровней адипонектина с показателями липидного и углеводного обмена у юношей и мужчин с ожирением, манифестировавшим в пубертатный период // Известия высших учебныхзаведений. Поволжский регион. Медичинские науки. 2011. — T. 18. — №2. — C. 11-18. [Mitroshina YeV. Vzaimosvyaz' urovney adiponektina s pokazatelyami lipidnogo i uglevodnogo obmena u yunoshey i muzhchin s ozhireniyem, manifestirovavshim v pubertatnyy period. Izvestiya vysshikh uchebnykh zavedeniy. Povolzhskiy region. 2011;18(2):11-18. (in Russ.)].

53. Banerjee A, Khemka VK, Roy D, et al. Role of Serum Adiponectin and Vitamin D in Prediabetes and Diabetes Mellitus. Can J Diabetes. 2017;41(3):259-265. doi: https://doi.org/10.1016/j.jcjd.2016.10.006

54. Abdella NA, Mojiminiyi OA. Clinical Applications of Adiponectin Measurements in Type 2 Diabetes Mellitus: Screening, Diagnosis, and Marker of Diabetes Control. Dis Markers. 2018;2018:1-6. doi: https://doi.org/10.1155/2018/5187940 
55. Reinehr T, Woelfle J, Wiegand S, et al. Leptin but not adiponectin is related to type 2 diabetes mellitus in obese adolescents. Pediatr Diabetes. 2016;17(4):281-288. doi: https://doi.org/10.1111/pedi.12276

56. Недогода С.В., Чумачек Е.В., Цома В.В., и др. Возможности азилсартана в коррекции инсулинорезистентности и уровня адипокинов при артериальной гипертензии в сравнении с другими сартанами // Российский кардиологический журнал. - 2019. - №1. - C. 70-79. [Nedogoda SV, Chumachek EV, Tsoma WV, et al. Effectiveness of in insulin resistance correction and the adipokines level reduction in patients with arterial hypertension in comparison with other ARBs. Russian Journal of Cardiology. 2019;1:70-79. (In Russ.)]. doi: https://doi.org/10.15829/1560-4071-2019-1-70-79

57. Недогода С.В., Чумачек Е.В., Цома В.В., и др. Возможности азилсартана медоксомила в коррекции инсулинорезистентности и уровня адипокинов при артериальной гипертензии в сравнении с ингибиторами ангиотензинпревращающего фермента // Российский кардиологический журнал. - 2020. T. 25. — №7. - C. 3767 [Nedogoda SV, Chumachek EV, Tsoma VV, et al. Azilsartan medoxomil for improving insulin resistance and adipokine levels in hypertension in comparison with angiotensinconverting enzyme inhibitors. Russ J Cardiol. 2020;25(7):3767. (In Russ.)]. doi: https://doi.org/10.15829/1560-4071-2020-3767

58. Knights AJ, Funnell AP, Pearson RC, et al. Adipokines and insulin action: A sensitive issue. Adipocyte. 2014;3(2):88-96. doi: https://doi.org/10.4161/adip.27552

59. Derosa G, Catena G, Gaudio G, et al. Adipose tissue dysfunction and metabolic disorders: Is it possible to predict who will develop type 2 diabetes mellitus? Role of markErs in the progreSsion of dlabeteS in obese paTleNts (The RESISTIN trial). Cytokine. 2020;127:154947. doi: https://doi.org/10.1016/j.cyto.2019.154947

60. Park HK, Kwak MK, Kim HJ, Ahima RS. Linking resistin, inflammation, and cardiometabolic diseases. Korean J Intern Med. 2017;32(2):239-247. doi: https://doi.org/10.3904/kjim.2016.229

61. Cobbold C. Type 2 diabetes mellitus risk and exercise: is resistin involved? J Sports Med Phys Fitness. 2019;59(2):290-297. doi: https://doi.org/10.23736/S0022-4707.18.08258-0

62. Park HK, Ahima RS. Resistin in rodents and humans. Diabetes Metab J. 2013;37:404-414. doi: https://doi.org/10.4093/dmj.2013.37.6.404

63. Menzaghi C, Bacci S, Salvemini L, et al. Serum resistin, cardiovascular disease and all-cause mortality in patients with type 2 diabetes. PLoS One. 2014;8:e64729. doi: https://doi.org/10.1371/journal.pone.0064729

64. Losano G, Folino A, Rastaldo R. Role of three adipokines in metabolic syndrome. Pol Arch Med Wewn. 2016;126(4):219-221. doi: https://doi.org/10.20452/pamw.3386

65. Jamaluddin MS, Yan S, Lu J, et al. Resistin increases monolayer permeability of human coronary artery endothelial cells. PLoS One. 2013;8:e84576. doi: https://doi.org/10.1371/journal.pone.0084576

66. Khera AV, Qamar A, Murphy SA, et al. On-statin resistin, leptin, and risk of recurrent coronary events after hospitalization for an acute coronary syndrome (from the pravastatin or atorvastatin evaluation and infection therapy-thrombolysis in myocardial infarction 22 study). Am J Cardiol. 2015;116:694-698. doi: https://doi.org/10.1016/j.amjcard.2015.05.038

67. Авсарагова А.3., Астахова 3.Т., Ремизов О.В. Влияние адипокина резистина на риск развития сердечно-сосудистых осложнений у больных с острым коронарным синдромом // Вестник новых медииинских технологий. - 2019. - Т. 4. C. 49-52. [Avsaragova AZ, Astahova ZT, Remizov OV. Influence of adipokine resistin on the risk of development of cardiovascular complications in patients with acute coronary syndrome. Journal of New Medical Technologies. 2019;4:49-52. (in Russ.)]. doi: https://doi.org/10.24411/1609-2163-2019-16513

68. Badoer E, Kosari S, Stebbing MJ. Resistin, an adipokine with nongeneralized actions on sympathetic nerve activity. Front Physiol. 2015;6:321. doi: https://doi.org/10.3389/fphys.2015.00321

69. Федотова А.В., Чернышева Е.Н., Панова Т.Н. Взаимосвязь сывороточного лептина и плазменного апелина у мужчин с метаболическим синдромом // Альманах клинической медицины. - 2016. - Т. 4. - №4. - C. 457-461. [Fedotova AV, Chernysheva EN, Panova TN, Akhtyamova KV. The relationship of serum leptin and plasma apelin levels in men with metabolic syndrome. Almanac of Clinical Medicine. 2016;44(4):457-461. (in Russ.)]. doi: https://doi.org/10.18786/2072-0505-2016-44-4-457-461

70. Boucher J, Masri B, Daviaud D, et al. Apelin, a newly identified adipokine up-regulated by insulin and obesity. Endocrinology. 2005;146:1764-1771. doi: https://doi.org/10.1210/en.2004-1427

71. Ma WY, Yu TY, Wei JN, et al. Plasma apelin: A novel biomarker for predicting diabetes. Clin Chim Acta. 2014;435:18-23. doi: https://doi.org/10.1016/j.cca.2014.03.030

72. Habchi M, Duvillard L, Cottet $V$, et al. Circulating apelin is increased in patients with type 1 or type 2 diabetes and is associated with better glycaemic control. Clin Endocrinol (Oxf). 2014;81(5):696-701. doi: https://doi.org/10.1111/cen.12404

73. Zhang $\mathrm{BH}$, Wang $\mathrm{W}$, Wang $\mathrm{H}$, et al. Promoting effects of the adipokine, apelin, on diabetic nephropathy. PLoS One. 2013;8(4):e60457. doi: https://doi.org/10.1371/journal.pone.0060457

74. Федотова А.В., Панова Т.Н., Демидов А.А., Чернышева Е.Н. Плазменный апелин у пациентов с артериальной гипертонией и ожирением // Кардиологический вестник. - 2015. T. 10. - №4. - C. 44-48. [Fedotova AV, Panova TN, Demidov AA Chernysheva YeN. Apelin plasma level in patients with arterial hypertension and obesity. Kardiologicheskiy vestnik. 2015;10(4):44-48. (In Russ.)]

75. Коваль С.Н., Юшко К.А., Старченко Т.Г. Апелин крови у больных гипертонической болезнью с сахарным диабетом 2 типа и без такого в динамике комбинированной терапии. Научный результат. - 2014. - T. 1. — №2. - C. 4-11. [Koval SN, Yushko KA, Starchenko TG. Apelin of blood in patients with essential hypertension and type 2 diabetes and without it in the dynamics of combined therapy. Nauchnyy rezul'tat. 2014;1 (2):4-11. (In Russ.)]

76. Xie H, Luo G, Zheng Y, et al. Lowered circulating apelin is significantly associated with an increased risk for hypertension: A meta-analysis. Clin Exp Hypertens. 2017;39(5):435-440. doi: https://doi.org/10.1080/10641963.2016.1267199

\section{ИНФОРМАЦИЯ ОБ АВТОРАХ [AUTHORS INFO]:}

*Вербовой Андрей Феликсович, д.м.н., профессор [Andrey F. Verbovoy, MD, PhD, Professor]; адрес: 443099, Самара, ул. Чапаевская, д. 89 [address: 89 Chapaevskaya street, 443099 Samara, Russia]; ORCID: https://orcid.org/0000-0001-6123-5610; eLibrary SPIN: 2923-6745; e-mail: andreyy.verbovoyy@rambler.ru

Вербовая Нэлли Ильинична, д.М.Н., професcop [Nelly I. Verbovaya, MD, PhD, Professor]; ORCID: https://orcid.org/0000-0002-8788-9759; eLibrary SPIN: 9321-3659; e-mail: diabet@samtel.ru Долгих Юлия Александровна, к.м.н. [Yuliya A. Dolgikh, MD, PhD]; ORCID: https://orcid.org/0000-0001-6123-5610; eLibrary SPIN: 3266-3933; e-mail: yulyadoll@mail.ru

*Автор, ответственный за переписку / Corresponding author.

\section{ЦИТИРОВАТЬ:}

Вербовой А.Ф., Вербовая Н.И., Долгих Ю.А. Ожирение - основа метаболического синдрома // Ожирение и метаболизм. - 2021. — Т. 18. — №2. - С. 142-149. doi: https://doi.org/10.14341/omet12707

\section{TO CITE THIS ARTICLE:}

Verbovoy AF, Verbovaya NI, Dolgikh YA. Obesity is the basis of metabolic syndrome. Obesity and metabolism. 2021;18(2):142-149. doi: https://doi.org/10.14341/omet12707 